\title{
RHABDOMYOBLASTS IN CEREBROSPINAL FLUID
}

Deepak Nayak M, Sushma V. Belurkar.

1. Assistant Professor, Department of Pathology, Melaka Manipal Medical College, Manipal, Manipal University

2. Associate Professor, Department of Pathology, Kasturba Medical College. Manipal, Manipal University

\section{CORRESPONDING AUTHOR}

Dr. Deepak Nayak M.

Department of Pathology,

Melaka Manipal Medical College,

Manipal University, Manipal, India.

E-mail: deepzienator@gmail.com

Ph: 00919901920537.

Rhabdomyosarcoma (RMS) is an aggressive soft tissue malignancy, not uncommonly seen in adults. The location of this malignancy is quite ubiquitous. However, a parameningeal location is uncommon and accounts for about $16 \%$ of all rhabdomyosarcomas. We report an instance where rhabdomyoblasts were seen infiltrating the cerebrospinal fluid (CSF).

A 35 year old female patient presented to our hospital with the primary complaints of bilateral nose block and left sided headache since1month. Clinically, a deviated nasal septum was diagnosed which needed a septal surgery. Since the hematological parameters showed a pancytopenia, the surgery was postponed. The patient presented 3 weeks later with additional complaints of worsening headache and significant blurring of vision in her left eye. The MRI scan revealed a midline, dural-based mass. A therapeutic tap of the cerebrospinal fluid sent to the clinical laboratory for analysis which showed large abnormal cells (figure 1). The bone marrow also showed similar cells, with karyomegaly, dense chromatin, and coalescing vacuoles which were Periodic Acid Schiff (PAS) negative. The biopsy from the mass was diagnosed as rhabdomyosarcoma (parameningeal type). Immunohistochemistry showed positivity for Myogenin and Myo-D1.

Rhabdomyosarcoma(RMS) is an aggressive soft tissue malignancy, not uncommonly seen in adults.(1)Bone marrow involvement is found in about $29 \%$ of RMS patients in clinical stage IV.(2) Parameningeal RMS represent $16 \%$ of all sarcomas but less than $10 \%$ present with pancytopenia.(3) A simultaneous marrow involvement with CSF spread is an extremely rare phenomenon.(4)The spread portends a poor prognosis. (5)Morphologically; such cases pose serious diagnostic challenges to a hematopathologist. A multidisciplinary approach comprising of histology, IHC on bone marrow biopsy and radiology are crucial to achieve the diagnosis of RMS.

\section{REFERENCES:}

1. Weiss SW, Goldblum JR. Rhabdomyosarcoma. Enzinger and Weiss's Soft Tissue Tumors, fifth ed. Weiss SW and Goldblum JR (editors),Elsevier,China 2008:595-632.

2. Parham DM, Barr FG. Alveolar Rhabdomyosarcoma. In: World Health Organization (WHO) Classification of Tumors. Pathology and Genetics of tumors of Soft Tissues and Bone. Fletcher CDM, Unni KK, Mertens F (editors).IARC press.Lyon 2002:150-152. 
3. Reid MM et al. Alveolar rhabdomyosarcoma infiltrating bone marrow at presentation: the value to diagnosis of bone marrow trephine biopsy specimen. J Clin Pathol 1992; 45:759-762.

4. Etcubanas E, Peiper S, Stass S, Green A. Rhabdomyosarcoma, presenting as disseminated malignancy from an unknown primary site: a retrospective study of 10 pediatric cases. Med PediatrOncol 1989; 17:39-44.

5. Breneman JC, Lyden E, Pappo AS et al. Prognostic factors and clinical outcomes in children and adolescents with metastatic rhabdomyosarcoma- a report from the Intergroup Rhabdomyosarcoma Study IV. J Clin Oncol 2003; 21:78-84.

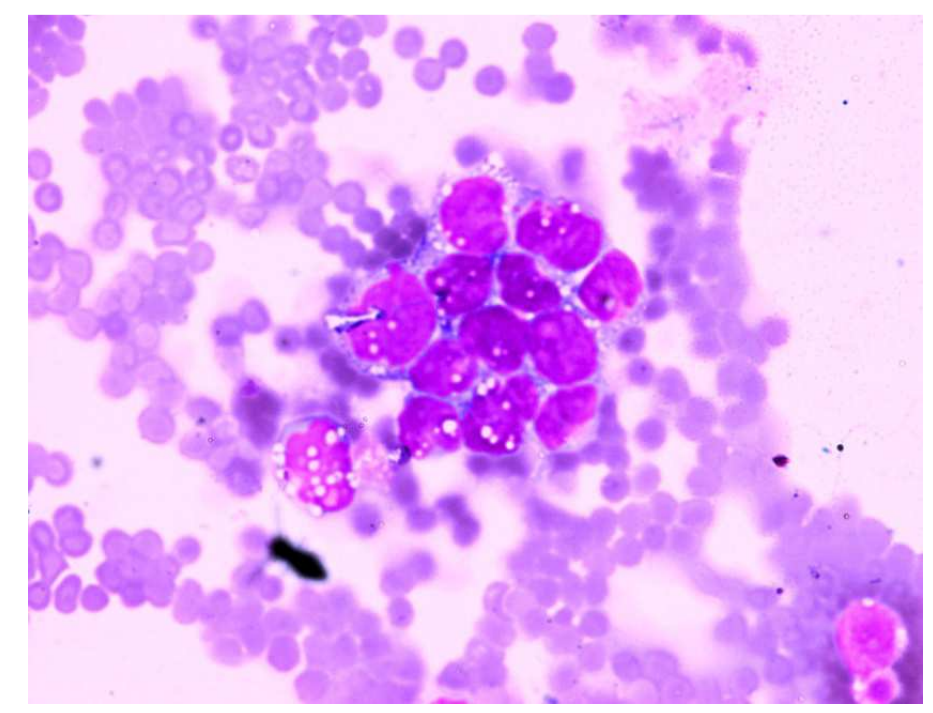

Figure 1: Pleomorphic features comprising of moderate to abundant vacuolated cytoplasm, round nucleus with dense chromatin; few with prominent nucleoli (Leishman x100) 